\title{
PENGARUH TEMPERATUR KARBONASI TERHADAP KARAKTERISTIK PEMBAKARAN BRIKET SAMPAH KOTA
}

\author{
Dwi Aries Himawanto \\ Jurusan Teknik Mesin Universitas Negeri Sebelas Maret Surakarta \\ Kampus Kentingan Surakarta \\ email :dwiaris@uns.ac.id
}

\begin{abstract}
The aim of the research was find out the effect of carbonization temperature to the combustion characteristic of Municipal Solid Waste (MSW) briquette as an alternative solid fuel.

The broquette manufacturing started when the MSW with contain $10 \%$ weight of non organic matter crushed into litle pieces, limestone and mollases as a binder, and pressed in pressing machine. The formed biobriquette were taken into a carbonization furnace to carbonize in three diferent temperature i.e. $80^{\circ} \mathrm{C}, 120^{\circ} \mathrm{C}$, and $140^{\circ} \mathrm{C}$, then taken into furnace to find the combustion characterictics.

The results of the research show that the $120{ }^{\circ} \mathrm{C}$ carbonize briquette give the best combustion performance.
\end{abstract}

Keywords: briquette, MSW, combustion characteristic, carbonization

\section{PENDAHULUAN}

Pada saat ini, laju konsumsi bahan bakar semakin tinggi seiring dengan semakin banyaknya populasi penduduk dunia dan tingginya laju perkembangan industri. Hal ini membawa kekhawatiran akan semakin menipisnya cadangan bahan bakar fosil dan juga muncul kekhawatiran akan semakin tinginya laju polusi yang ditimbulkan oleh pembakaran bahan bakar fosil, sehingga sumber energi alternatif semakin menjadi tumpuan bagi pemecahan masalah tersebut.

Sementara disisi lain, permasalahan sampah kota semakin menjadi permasalahn yang pelik di berbagai kota besar karena keterbatasan lahan dan semakin tingginya produksi sampah kota yang dihasilkan, hal tersebut berakibat pada semakin menumpuknya sampah kota dan menjadi sumber permasalahan lingkungan yang utama, berbagai usaha telah ditempuh untuk mengatasi hal tersebut, diantaranya dibuat kompos dan dibakar dalam incinerator namun keduanya masih mengandung berbagai permasalahan yaitu tingginya kandungan logam berat dalam kompos dan tingginya polusi dioxin bila pembakaran tidak berjalan sempurna. Padahal apabila sampah kota tersebut diolah didapat satu bahan bakar alternatif yang bernama biobriket, yang salah satu variable yang penting adalah komponen non biodegradable dalam sampah kota yang perlu diperhatikan dan cara pengolahan briket itu sendiri dengan cara karbonasi., oleh karena itulah dalam kesempatan kali ini, akan dipaparkan pengaruh temperatur karbonasi dalam briket sampah kota yang memiliki kandungan bahan anorganik sebesar $10 \%$

Potensi sampah kota di Indonesia pada tahun 2000 adalah sebesar 100.000 ton per hari, dari sekian banyak sampah kota yang dihasilkan tersebut sampah plastik mempunyai sumbangan sebesar $2 \%$ sehingga dalam satu hari dapat dihasilkan 2.000 ton perhari, sedangkan kondisi 
Surakarta potensi sampah plastik sebesar 5,34 ton per hari (Sudrajat, 2004) dalam Boavida dkk.(2002) menjelaskan penelitiannya mengenai pembakaran batu bara dengan limbah kertas dan plastik yang tak mampu daur ulang di dalam Fluidized Bed Reactor, menjelaskan bahwa karakter pembakaran campuran batu bara bara dan sampah kertas dan plastik tergantung pada pengolahan sampah itu sendiri, juga didapatkan hasil bahwa proses pembakaran campuran tersebut bagus. Sedangkan udara berlebih dan temperatur pembakaran merupakan parameter penting dalam pembakaran. Sedangkan penambahan limestone akan menurunkan kadar emisi $\mathrm{SO}_{2}$ dan juga emisi logam berat tidak ada perbedaan apabila dibandingkan dengan pembakaran batu bara tunggal.Li dkk. (1999) dalam penelitiannya mengenai pembakaran bersama Municipal Solid Waste (MSW, sampah kota) yang di dalamnya termasuk sampah plastik, dengan batu bara dalam Fluidized Bed Reactor menyatakan bahwa pembakaran bersama antara batu bara dan sampah kota berlangsung efektif dan prosesnya steady dan juga didapatkan emisi polutan yang rendah.

\section{TINJAUAN PUSTAKA}

Amorini dkk. (2002) yang melakukan penelitian mengenai pembakaran antara batu bara dan sampah kota yang telah diolah guna mendapatkan listrik menjelaskan bahwa pembakaran bersama tersebut memiliki operasional tinggi dan menaikkan efisiensi proses pembakaran itu sendiri disamping itu didapatkan bahwa proses pembakaran itu sendiri akan menurunkan kadar emisi dioxin dan furan. Biagini dkk. (2002) dalam penelitiannya mengenai pilot plant pembakaran bersama antara batu bara dan sampah ban menyatakan bahwa pembakaran bersama antara batu bara dan sampah ban layak dilaksanakan sepanjang tidak ada permasalahan dengan cara pemasukan sampah ban dan batu bara dalam tungku sedangkan emissi polusi yang terjadi juga dapat diterima dalam ambang batas yang diijinkan.

Stevanovic dkk. (2002) yang melakukan penelitian mengenai pengaruh konsentrasi fibreglass dalam pembakaran komposit polyproylene/fibreglass menyatakan bahwa karakter pembakaran material komposit polyproylenelfibreglass merupakan fungsi dari konsentrasi fibreglass dalam komposit tersebut dan juga tergantung pada jenis komposit yang bersangkutan.

Pembakaran bahan bakar padat memilki tahapan-tahapan tertentu, tahapan-tahapan tersebut adalah sebagai berikut :

1. Pengeringan

2. Devolatilisasi

3. Pembakaran Arang

Sedangkan faktor-faktor yang mempengaruhi pembakaran bahan bakar padat antara lain sebagai berikut :

1. Ukuran Partikel

2. Kecepatan aliran udara

3. Temperatur Pembakaran

4. Jenis Bahan Bakar

\section{METODE PENELITIAN}

Bahan Penelitian

Bahan-bahan yang digunakan dalam penelitian ini adalah sampah kota didapatkan dari TPS-TPS di Surakarta, , tetes tebu (molasses) sebagai bahan pengikat bahan briket, batu kapur (limestone) sebagai bahan pengikat polutan Alat Penelitian

Alat penelitian yang digunakan dapat dilihat pada gambar 1. 


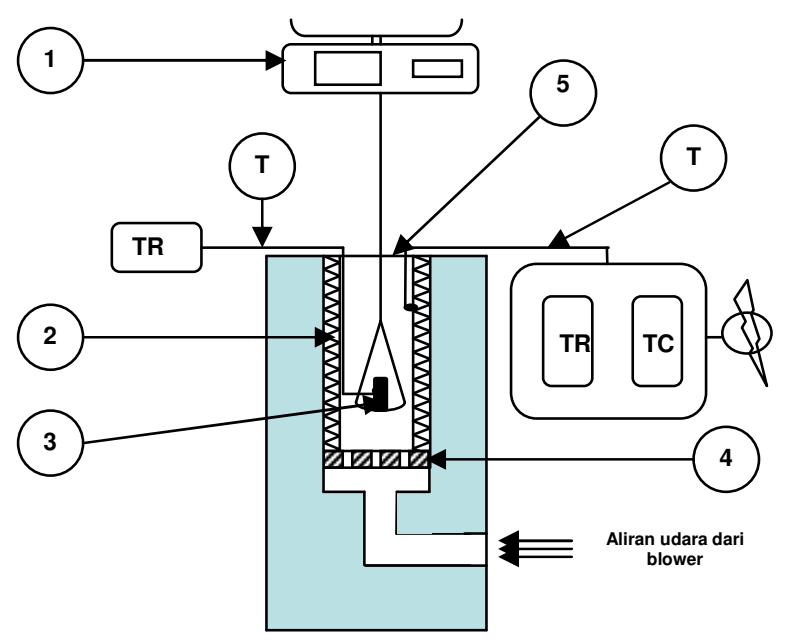

Gambar 1. Alat Penelitian

\section{Cara Penelitian}

Sampah kota dengan perbandingan 90 $\%$ organik dan $10 \%$ anorganik yang akan dibuat briket dihancurkan dengan jalan dihancurkan sehingga menjadi halus dengan ukuran yang homogen kemudian dicampur batu kapur dan ditambahkan media perekat berupa tetes tebu kemudian ditekan dalam mesin pres sehingga keluaran yang didapatkan berupa briket berbentuk silindris. Briket yang telah didapatkan kemudian dimasukkan kedalam tempat karbonisasi dan dikarbonisasi pada temperatur $80^{\circ} \mathrm{C}, \quad 120^{\circ} \mathrm{C}$ dan $.140^{\circ} \mathrm{C}$. Setelah dikarbonisasi kemudian briket tersebut dibakar dalam alat uji pembakaran. Adapun kecepatan aliran udara yang digunakan adalah $0,2 \mathrm{~m} / \mathrm{s}$. Penelitian diadakan pada kondisi temperatur udara luar $28^{0} \mathrm{C}-34^{0} \mathrm{C}$

\section{HASIL DAN PEMBAHASAN}

Pengaruh Variasi Kapasitas Aliran

Sifat-sifat dari bahan dasar dalam penelitian ini ditampilkan dalam tabel 1 .

Tabel 1. Sifat-Sifat Bahan Dasar

\begin{tabular}{lcc}
\hline \multicolumn{1}{c}{ Sifat } & $\begin{array}{c}\text { Sampah Kota } \\
\mathbf{1 0 0} \% \text { organik }\end{array}$ & $\begin{array}{c}\text { Sampah Kota } \\
\mathbf{9 0} \% \text { organik }\end{array}$ \\
\hline Kadar air (\%) & 10,099 & 9,433 \\
Kadar abu (\%) & 12,100 & 11,045 \\
Fixed Carbon (\%) & 8,510 & 7,033 \\
Volatile Matter (\%) & 69,291 & 72,489 \\
\hline
\end{tabular}

Pada table 1 terungkap bahwa kandungan volatile matter akan sangat berperanan dalam menentukan sifat pembakaran, tampak bahwa kandungan volatile matter sampah kota $90 \%$ organik lebih tinggi, kandungan volatile matter yang tinggi akan menyebabkan proses pembakaran substansi tersebut akan lebih mudah. 
Sedangkan perbandingan karakteristik pembakaran antara briket sampah kota 100 $\%$ organik dan $90 \%$ organik dapat dilihat dalam gambar 2 dan gambar 3. Dari gambar hasil penelitian tersebut dapat dilihat adanya kadar anorganik dalam briket akan membuat turunnya nilai temperatur pembakaran yang dihasilkan namun kecepatan pembakaran akan membaik dengan naiknya kadar namun dengan adanya kadar anorganik, hal ini disebabkan karena dengan adanya penambahan kadar anorganik akan menaiikan kndungan volatile matter yang akan mempercepat terjadi pembakaran seperti terlihat dalam tabel 1, namun dengan adanya kadar anorganik diduga akan menurunkan nilai kalor dari briket yang dibuat sehingga temperatur pembakaran yang dihasilkan menurun

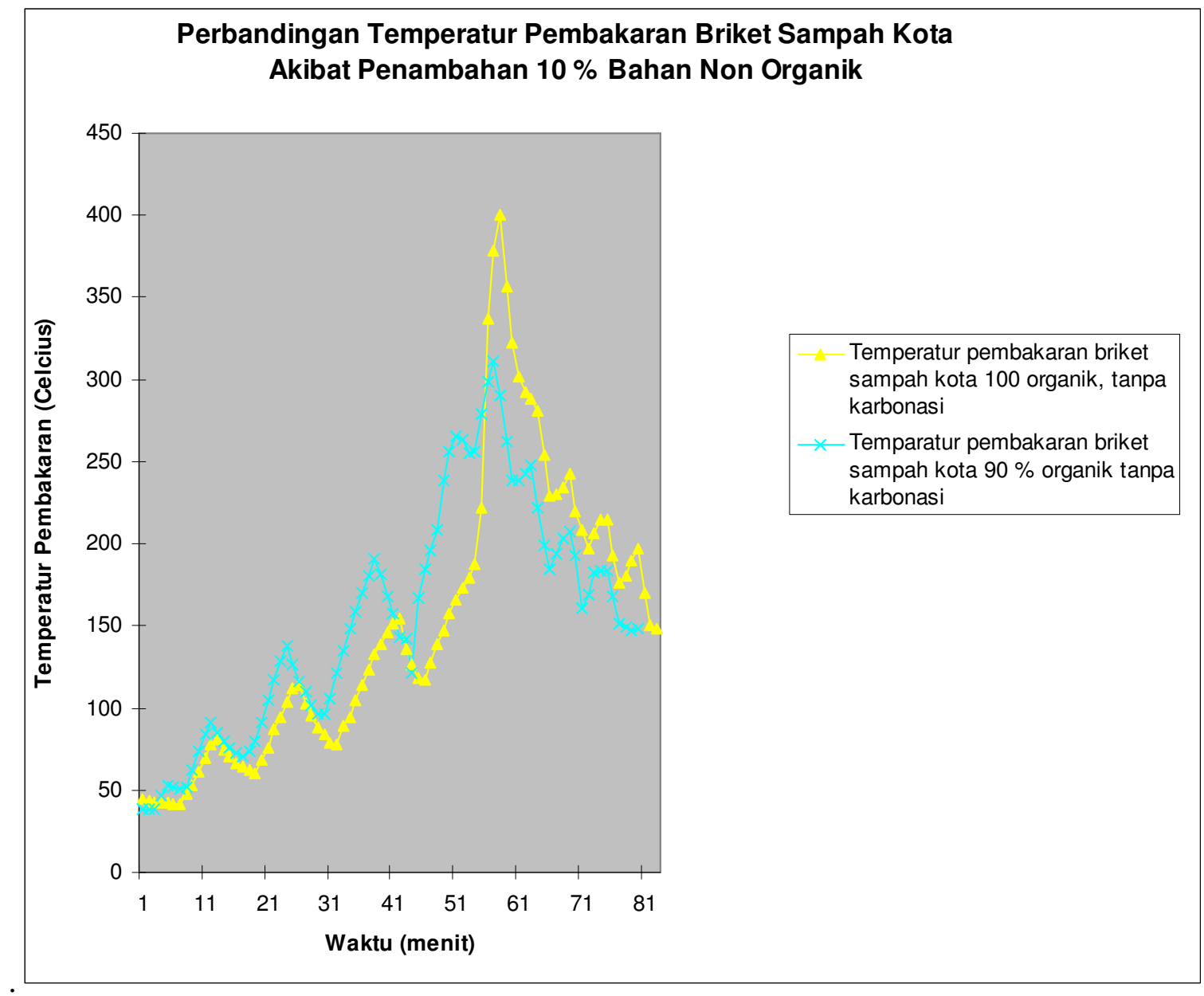

Gambar 2. Grafik Perbandingan Temperatur Pembakaran Briket Sampah Kota Akibat Penambahan $10 \%$ Bahan Non Organik 


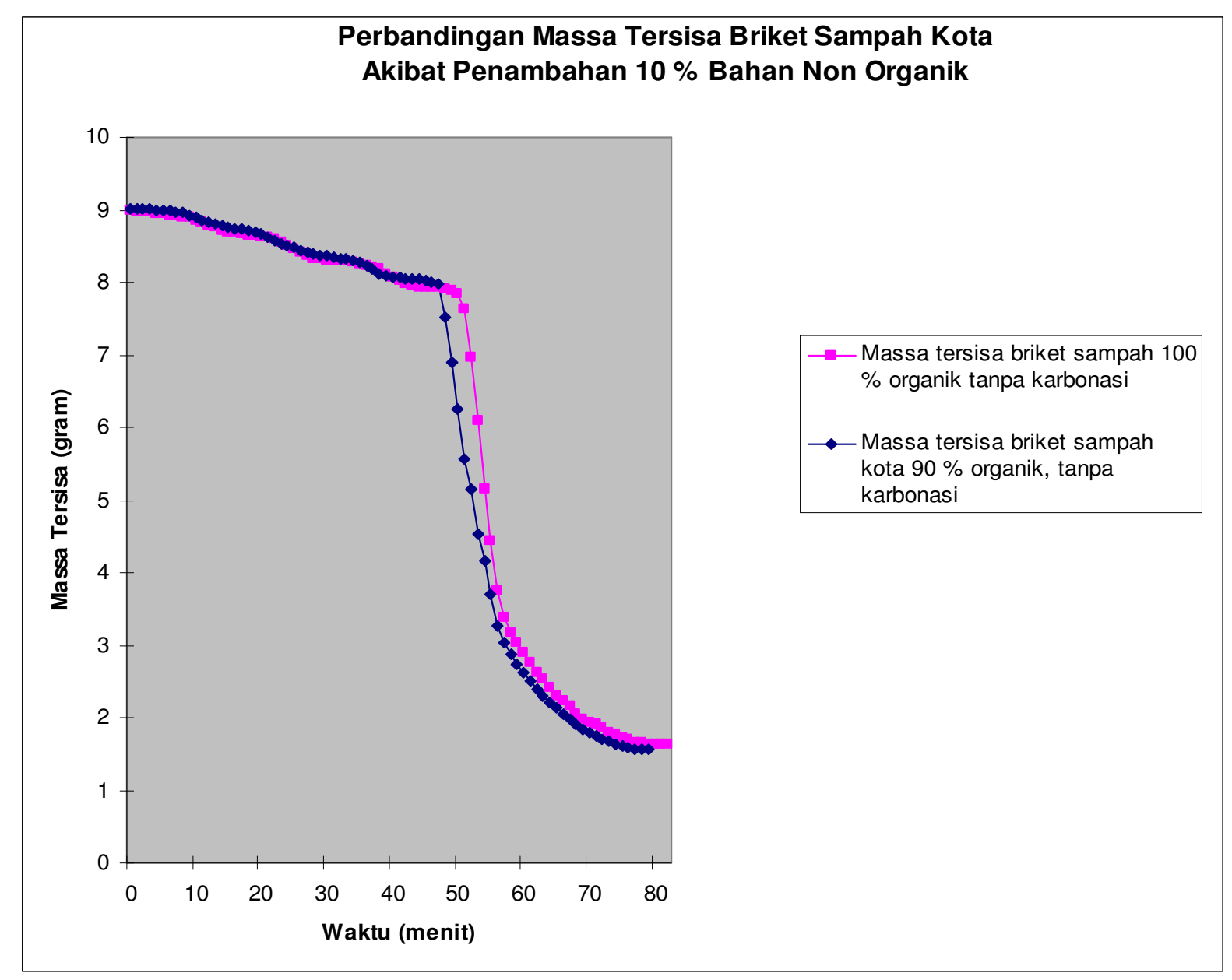

Gambar 3. Grafik Perbandingan Massa Tersisa Briket Sampah Kota Akibat Penambahan $10 \%$ Bahan Non Organik

Sementara itu, pengaruh temperatur karbonasi terhadap briket sampah dengan kadar $90 \%$ organik dapat dilihat dalam gambar 4 dan gambar 5, dari gambargambar tersebut diatas dapat dilihat bahwa tinggi temperatur karbonasi memililki pengaruh yang signifikan terhadap karakteristik pembakaran briket, kenaikan temperatur karbonasi tidak dengan serta merta menaikkan karakteristik pembakaran briket sampah kota, namun terdapat kondisi optimal untuk menghasilkan karakteristik pembakaran terbaik.

Dapat dilihat dari gambar 4, kecepatan pembakaran terbaik dimilliki oleh briket terkarbonasi $80{ }^{0} \mathrm{C}$ diikuti oleh briket terkarbonasi $120{ }^{0} \mathrm{C}$, kemudian briket terkarbonasi $140{ }^{\circ} \mathrm{C}$ dan terakhir briket tak terkarbonasi . Hal ini disebabkan proses karbonisasi menyebabkan kandungan volatile matter didalam briket menguap namun diimbangi oleh perubahan struktur partikel didalam briket yang berimbas pada porositas briket, salah satu faktor penting dalam penentuan karakteristik pembakaran.

Sementara itu, temperatur pembakaran yang dihasilkan, tertinggi dimiliki oleh briket terkarbonasi $120{ }^{\circ} \mathrm{C}$ sebesar $448,8{ }^{0} \mathrm{C}$ kemudian diikuti oeh briket terkarbonasi 80 ${ }^{0} \mathrm{C}$ dengan temperatur pembakaran sebesar $374,3{ }^{\circ} \mathrm{C}$, briket terkarbonasi $140{ }^{\circ} \mathrm{C}$ yang menghasilkan temperatur $339,2{ }^{0} \mathrm{C}$ dan terakhir briket tak terkarbonasi dengan temperatur yang dihasilkan sebesar 310,9 ${ }^{0} \mathrm{C}$. 
Sedangkan temperatur pembakaran yang dihasilkan oleh pembakaran briket sampah kota dengan $100 \%$ organik tanpa karbonasi adalah sebesar $400,1{ }^{0} \mathrm{C}$. Sehingga briket hasil karbonasi yang karakteristiknya lebih baik dari pada briket sampah kota $100 \%$ organik adalah briket sampah kota $90 \%$ organik terkarbonasi 120 ${ }^{0} \mathrm{C}$. Hal ini dipertegas oleh ketermudahan penyalaan briket sampah kota $100 \%$ organik dapat disamai oleh briket sampah kota $90 \%$ organik terkarbonasi $120{ }^{0} \mathrm{C}$, seperti terlihat dalam tabel 2.

Tabel 2 Temperatur Terbakar Briket sampah Kota

\begin{tabular}{|c|c|c|}
\hline No. & Sampel & $\begin{array}{c}\text { Mulai Terbakar Pada Temperatur } \\
\left({ }^{0} \text { Celcius }\right)\end{array}$ \\
\hline 1. & Sampah Kota $100 \%$ organik tanpa karbonasi & 172,5 \\
\hline 2. & Sampah Kota $90 \%$ organik tanpa karbonasi & 208 \\
\hline 3. & $\begin{array}{l}\text { Sampah Kota } 90 \% \text { organik karbonasi pada } \\
80{ }^{\circ} \mathrm{C}\end{array}$ & 181,1 \\
\hline 4. & $\begin{array}{l}\text { Sampah Kota } 90 \% \text { organik karbonasi pada } \\
120{ }^{\circ} \mathrm{C}\end{array}$ & 176,3 \\
\hline 5. & $\begin{array}{l}\text { Sampah Kota } 90 \% \text { organik karbonasi pada } \\
140{ }^{0} \mathrm{C}\end{array}$ & 184,9 \\
\hline
\end{tabular}

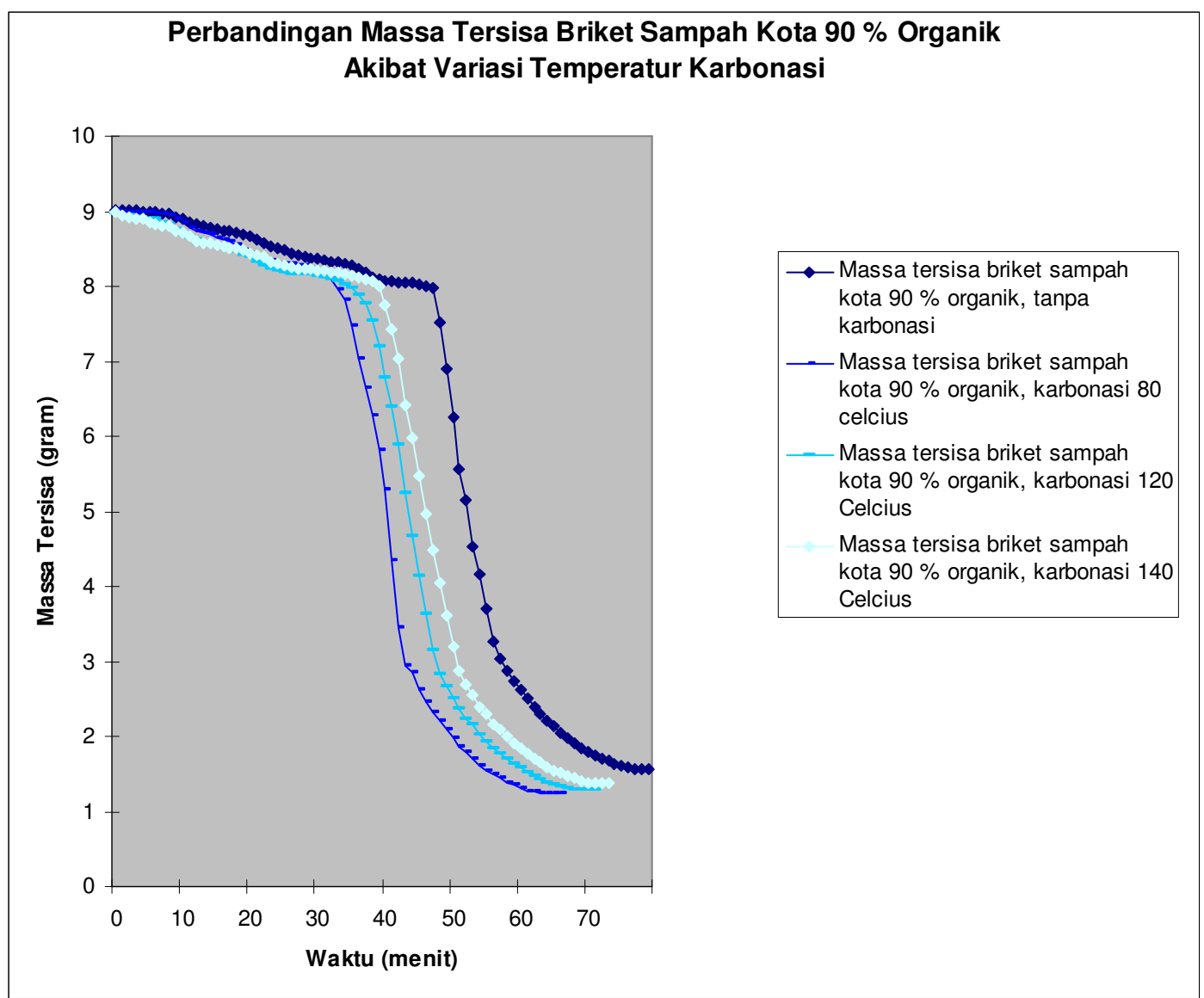

Gambar 4. Grafik Perbandingan massa Tersisa Briket Sampah Kota $90 \%$ Organik Akibat Variasi Temperatur karbonasi 


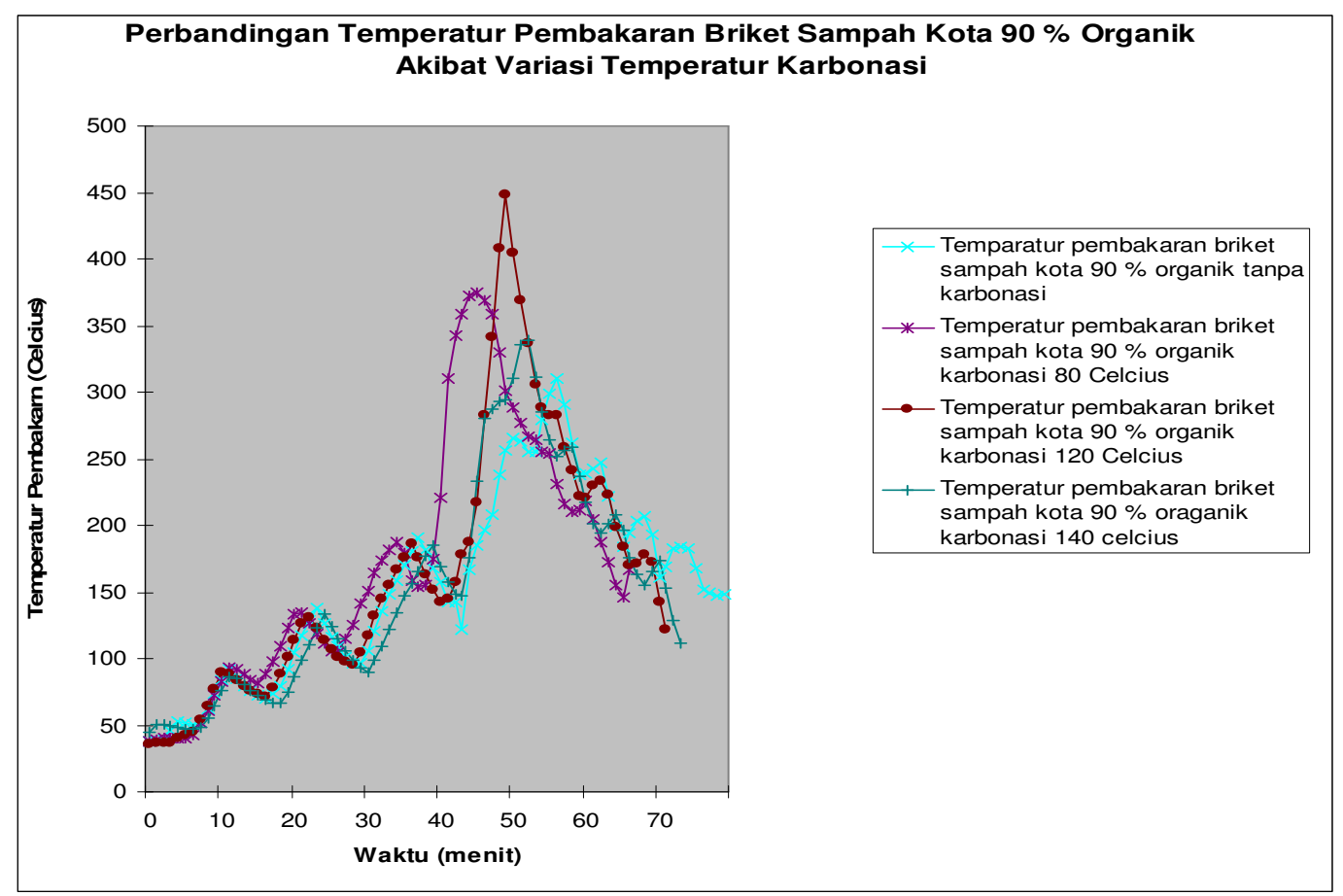

Gambar 5. Grafik Perbandingan Temperatur Pembakaran Briket Sampah Kota $90 \%$ Organik Akibat Variasi Temperatur Karbonasi

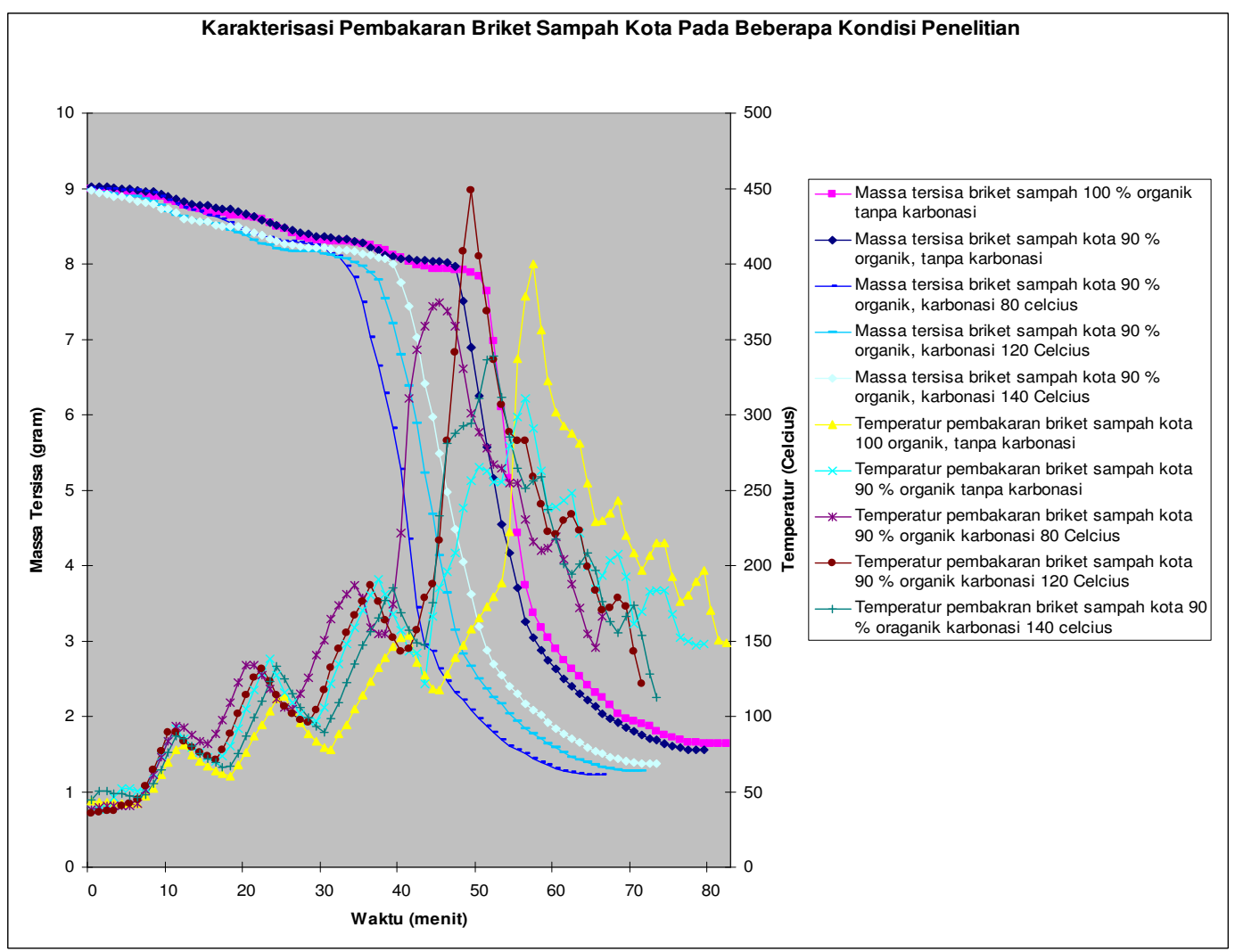

Gambar 6. Karakteristik Pembakaran Briket Sampah Kota Pada Beberapa Kondisi Penelitian 


\section{KESIMPULAN}

Dari hasil penelitian yang dilakukan dapat disimpulkan bahwa:

1. proses karbonasi akan mempengaruhi karakteristik pembakaran briket sampah kota, dimana tinggi temperatur karbonasi akan mempunyai pengarugh signifikan terhadap karakteristik pembakaran.

2. terdapat kondisi optimum tinggi temperatur karbonasi, hal ini berakibat kenaikan temperatur karbonasi yang terlalu tinggi justru akan mengurangi karakteristik pembakaran briket sampah kota.

3. karakteristik pembakaran terbaik dari briket sampah kota $90 \%$ organik yang diteliti terjadi pada kondisi karbonasi pada $120{ }^{\circ} \mathrm{C}$ dengan temperatur mulai terbakar pada $176,3{ }^{\circ} \mathrm{C}$, dengan peak temperatur yang dicapai sebesar $448,8^{\circ} \mathrm{C}$

\section{DAFTAR PUSTAKA}

Amorino,Carlo., Madeddu,Alessandra., Raggio,Gianni., Cau,Giorgio., Zotter,Thomas., 2002, Demonstration Plant of Co-combustion of Coal and on Site Pre-treted Waste in a Fluidized Bed for Electricity Production, CCT 2002

Biagini,E., Tognotti,L., Mallogni,S., Pasini,S., 2002, Co-Combustion of Coal and Tire Residue in A Pilot Plant : A Simplied Modeling approach For Scale-Up Predictions of Char Oxidation, Combust.Sci. and Tech, 174 (11\&12) pp. 129-150

Boavida,D., Abelha,P., Gulyurthu,I., Cabrita,I., 2002, Co-combustion of Coal and Non Recyclable Paper and Plastic Waste in a Fluidized Bed Reactor, ICCT, Sardinia, Italy, $21^{\text {st }}$ Oct

Himawanto, D.A, 2003, Pengolahan Limbah Pertanian menjadiBiobriket sebagai salah satu Bahan Bakar Alternatif, Laporan Akhir Penelitian Hibah Pekerti, Lembaga Penelitian Universitas Sebelas Maret Surakarta

Kiran,N., Ekinci,E., Snape,C.E., 2000, Recycling of Plastic Waste Via Pyrolisis, Resources Concervation and Recycling 29 (2000) pp. 273-283

Li Xiadong, Yan Jianhua, Chi Yang, Jiang Xuguang, 1999, Study of Fluidized Bed Combustion Technology Co-firing MSW and Coal : Its Application, Proceedings of The $15^{\text {th }}$ Intl. Conf. On Fluidized Bed Combustion, May 16-19, 1999, Savanah, Georgia.

Stevanovic,A., Mehta,S., Walther,D.C., Pello,Fernandes,A.C., 2002, The effect of Fiberglass concentration on The Piloted Ignition of Polypropylene/fibreglass Composite, Combustion Science. and Tech, 174 (11\&12) pp. 171-186

Sudradjat,R, 2004, The Potential of Biomass Energy Resources in Indonesia for the Possible Development of Clean Technology Process (CPT', Proceedings International Workshop on Biomass \& clean Fossil fuel Power Plant Technology, Jakarta, January 13-14,. 2004. 